\title{
DNA methylation enzyme inhibitor RG108 suppresses the radioresistance of esophageal cancer
}

\author{
YAO OU $^{1 *}$, QUAN ZHANG $^{2 *}$, YITING TANG $^{1}$, ZHONGHUA LU $^{1}$, \\ XUJING LU ${ }^{1}$, XIFA ZHOU ${ }^{1}$ and CHANGMIN LIU ${ }^{3}$ \\ ${ }^{1}$ Department of Radiotherapy, Changzhou Tumor Hospital, Soochow University, Changzhou, Jiangsu 213001; \\ ${ }^{2}$ Department of Radiotherapy, Huai'an First People's Hospital, Nanjing Medical University, Huai'an, Jiangsu 223300; \\ ${ }^{3}$ Department of Oncology, The Affiliated Hospital of Binzhou Medical College, Binzhou, Shandong 256603, P.R. China
}

Received July 7, 2017; Accepted December 15, 2017

DOI: $10.3892 /$ or.2018.6210

\begin{abstract}
Esophageal cancer (EC) is the eighth most common highly aggressive cancer worldwide. The purpose of this study was to investigate the effect of the DNA methyltransferase inhibitor RG108 on the radiosensitivity of EC cells. MTT and clonogenic assays were performed to assess the effect of RG108 on the proliferation and radiosensitivity of Eca-109 and TE-1 human EC cells. The cell cycle progression and alterations in apoptosis were analyzed by flow cytometry. For the in vivo analysis, the Eca-109 cells were inoculated into nude mice to establish tumors. Tissues from xenografts were obtained to detect changes to microvessels and tumor growth by immunohistochemistry (IHC). RNA-seq was used to identify differentially expressed genes. We found that RG108 increased the radiosensitivity of EC cells. Apoptosis and G2/M-phase arrest were induced by X-ray irradiation and were significantly enhanced by RG108. In addition, growth of tumor xenografts from the Eca-109 cells was significantly inhibited by irradiation in combination with RG108. The RNA-seq analysis revealed that, compared with radiation alone, X-ray irradiation in combination with RG108 altered the expression of 121 genes in multiple pathways, including the TGF- $\beta$ signaling pathway and the Epstein-Barr virus infection pathway. In conclusion, RG108 induced radiosensitivity in EC cells both in vitro and in vivo.
\end{abstract}

Correspondence to: Professor Xifa Zhou, Department of Radiotherapy, Changzhou Tumor Hospital, Soochow University, 68 Honghe Road, Xinbei, Changzhou, Jiangsu 213001, P.R. China E-mail: zhouxifacz@sina.com

Dr Changmin Liu, Department of Oncology, The Affiliated Hospital of Binzhou Medical College, 661 Yellow River Second Road, Binzhou, Shandong 256603, P.R. China

E-mail: byfylcm@126.com

*Contributed equally

Key words: RG108, methylation, esophageal cancer, radiosensitivity, apoptosis

\section{Introduction}

Esophageal cancer (EC) is the eighth most common highly aggressive gastrointestinal cancer and is the sixth leading cause of cancer-related deaths globally (1). In 1990 EC caused 345,000 deaths and this number rose to 400,000 in 2012 (2). The methods for diagnosing EC have since been improved and ionizing radiation (IR) now plays an important role in the treatment of human EC. Combining radiotherapy with chemotherapy improves the effects of treatment for advanced EC, however, the 5-year survival rate is still poor. Intrinsic radioresistance accounts for the high recurrence and poor 5 -year survival rate of patients with EC (3). Thus, there is an urgent need to extend our understanding of the molecular mechanisms underlying the progression of EC and provide new strategies to overcome EC radioresistance by manipulating key targets.

Multiple genetic and epigenetic alterations are involved in the growth of ECs, including tumor suppressor gene (TSG) mutations, loss of heterozygosity and promoter methylation, as well as overexpression of oncogenes $(4,5)$. However, the underlying molecular mechanisms that cause carcinogenesis are poorly understood. Epigenetic events, such as aberrant de novo methylation of gene promoters, have recently been defined as markers of human cancers and therapeutic strategies targeting these mechanisms are currently being tested in several clinical trials $(6,7)$. Among the compounds being tested, the DNA methyltransferase inhibitors (DNMTIs), such as decitabine (5-aza-2'-deoxycytidine), have been demonstrated to reverse the silencing of tumor-suppressor genes, such as PRKD1, TP53 and ESR1, thus upregulating their expression (8-10).

However, the effectiveness of these compounds depends on their incorporation into DNA, which may lead to dosedependent cytotoxicity (11). Due to the potential toxicity of nucleoside analogs, there has been a focus on discovering new compounds that may directly target DNMTs. RG108, a non-nucleoside analog designed to target human DNMT1, binds to the active site of DNMT and has been demonstrated to be effective in reactivating several tumor-suppressor genes in human colon cancer cells without affecting the methylation status of centromeric repeats (12). In addition, RG108 lacks the high levels of cytotoxicity associated with 5-Aza-dCR, which 
inhibits DNA methyltransferase activity to achieve DNA demethylation $(12,13)$. Thus, the aim of the present study was to assess the impact of RG108 on the viability, radiosensitization, apoptosis and cell cycle progression of EC cells.

\section{Materials and methods}

Cell culture and irradiation treatment. The commonly used esophageal squamous cancer cell lines Eca-109 and TE-1 which were obtained from the American Type Culture Collection (ATCC, Manassas, VA, USA) were maintained in Dulbecco's modified Eagle's medium (DMEM; HyClone Laboratories, Logan, UT, USA) containing $10 \%$ fetal bovine serum (FBS; HyClone Laboratories), $100 \mu \mathrm{g} / \mathrm{ml}$ streptomycin and $100 \mathrm{U} / \mathrm{ml}$ penicillin in a humidified incubator at $37^{\circ} \mathrm{C}$ with $5 \% \mathrm{CO}_{2}$. RG108 was purchased from Selleck Chemicals (Houston, TX, USA), dissolved in dimethyl sulfoxide (DMSO) and stored at $-20^{\circ} \mathrm{C}$ until use. The cells were pretreated with different concentrations of RG108 diluted in DMEM, followed by irradiation with a single dose of X-ray irradiation using a linear accelerator (Rad Source Technologies Inc., Suwanee, GA, USA) at a dose rate of $1.15 \mathrm{~Gy} / \mathrm{min}$ and $160 \mathrm{kV} \mathrm{X-ray}$ energy.

Cell viability assay. The viability of cells was evaluated using the 3-(4,5-dimethylthiazol-2-yl)-2,5-diphenyltetrazolium bromide (MTT) assay. The cells were seeded at a density of $2.5 \times 10^{3} /$ well in 96 -well flat bottom plates $24 \mathrm{~h}$ before treatment with RG108 and/or irradiation. The cells were then incubated at $37^{\circ} \mathrm{C}$ in a $5 \% \mathrm{CO}_{2}$ environment for $48 \mathrm{~h}$. Twenty microliters of a $5 \mathrm{mg} / \mathrm{ml}$ MTT solution were added into each well and the cells were incubated for another $4 \mathrm{~h}$. Then the supernatant was removed and the cells were lysed by adding $100 \mu 1$ of DMSO. The absorbance at $490 \mathrm{~nm}$ was assessed by an enzyme-linked immunosorbent assay reader. All tests were repeated three times independently.

Colony formation assay. The cells were seeded in triplicate into 6-well flat bottom plates at a density of 200-6,000 cells/well depending on the dose of radiation. Subsequently, the cells were treated with or without $25 \mu \mathrm{M}$ RG108 for $6 \mathrm{~h}$ and the supernatant was removed. Then, the cells were irradiated with $0,2,4,6$ or 8 Gy X-ray radiation and incubated for 12 days to form cell clones. Subsequently, the cells were fixed with methanol and stained with $0.1 \%$ crystal violet. The cells were manually counted under a dissecting microscope and clones were defined as groups of more than 50 cells. The radiation sensitivity enhancement ratios (SER) were calculated according to the multi-target single hit model. Each experiment was repeated three times.

Cell apoptosis and cell cycle analysis. The apoptotic cells were quantified using an Annexin V/7-aminoactinomycin D (7-AAD) double staining kit according to the manufacturer's instructions (BD Biosciences, San Jose, CA, USA). Briefly, the cells were exposed to $25 \mu \mathrm{M}$ RG108 for $6 \mathrm{~h}$ and then harvested $48 \mathrm{~h}$ after treatment with either 6 Gy of X-ray irradiation or sham treatment. The percentage of apoptotic cells was assessed with a FACSCalibur system (BD Biosciences). The percentage of both Annexin $\mathrm{V}^{+} / 7 \mathrm{AAD}^{-}$cells, early in the apoptotic process, and Annexin $\mathrm{V}^{+} / 7 \mathrm{AAD}^{+}$cells, in late apoptosis, was quantified.

For the cell cycle analysis, the cells were collected $24 \mathrm{~h}$ after treatment with RG108 or RG108 combined with 6 Gy of X-ray irradiation and fixed with $70 \%$ precooled ethanol overnight. After staining with propidium iodide (PI, $10 \mu \mathrm{g} / \mathrm{ml}$; Sigma-Aldrich, St. Louis, MO, USA) in the dark for $30 \mathrm{~min}$, flow cytometry was performed with a FACSCalibur system using ModFit LT software (Verity Software House Inc., Topsham, ME, USA).

Western blot analysis. The cells were harvested $48 \mathrm{~h}$ after treatment with RG108 and/or 6 Gy irradiation. Then they were incubated for $40 \mathrm{~min}$ on ice with ice-cold RIPA buffer (50 mM Tris pH 7.2, $150 \mathrm{mM} \mathrm{NaCl}, 1 \% \mathrm{NP}-40,1 \%$ sodium deoxycholate, $0.05 \%$ SDS and $1 \mathrm{mM} \mathrm{PMSF}$ ). After centrifugation at $4^{\circ} \mathrm{C}$ for $5 \mathrm{~min}$ at $12,000 \mathrm{x} \mathrm{g}$, supernatants were analyzed with an enhanced BCA protein assay kit (Beyotime Institute of Biotechnology, Nantong, China). The proteins were separated by sodium dodecyl sulfate polyacrylamide gel electrophoresis (SDS-PAGE) with 12\% gels and transferred onto polyvinylidene fluoride (PVDF) membranes. The gels were run and transferred under the same experimental conditions. The membranes were blocked with 5\% skim milk in TBS containing $0.1 \%$ Tween-20 (TBST) for $1 \mathrm{~h}$ at room temperature, followed by incubation overnight at $4^{\circ} \mathrm{C}$ with either Bax (1:200; mouse; cat. no. sc-20067) or Bcl-2 primary antibodies (1:1,000; mouse; cat. no. sc-7382; both from Santa Cruz Biotechnology, Santa Cruz, CA, USA). The membranes were washed three times in TBST and incubated with horseradish peroxidase-conjugated anti-mouse or anti-rabbit secondary antibodies (1:1,000; cat. no. A0192) for $2 \mathrm{~h}$ at room temperature. $\beta$-actin (Beyotime Institute of Biotechnology) was used as a loading control.

Tumor xenografts. We established a tumor transplantation model in BALB/c mice (SLAC Laboratory Animal Center, Shanghai, China) with Eca-109 cells. The mice were kept under specific pathogen-free conditions on a 12-h light-dark cycle. To produce tumors, $1 \times 10^{7}$ Eca-109 cells were suspended in $150 \mu 1$ of PBS and subcutaneously injected into each posterior flank region of 5-week-old male BALB/c nude mice $(\sim 18 \mathrm{~g})$. When the tumors reached $150-200 \mathrm{~mm}^{3}$, the mice were randomly divided into four groups as follows (5 mice/group): i) control (no radiation, injection of $100 \mu \mathrm{l}$ of sterile DMSO daily for 6 days); ii) RG108 alone (no radiation, injection of RG108 daily for 6 days, $50 \mathrm{mg} / \mathrm{kg}$ total in a volume of $100 \mu \mathrm{l}$ ); iii) IR plus DMSO (injection of $100 \mu 1$ of $0.01 \%$ sterile DMSO daily for 6 days, followed by 8 Gy radiation $1 \mathrm{~h}$ after the last DMSO injection); and iv) IR plus RG108 treatment (injection of RG108 daily for 6 days, $50 \mathrm{mg} / \mathrm{kg}$ total in a volume of $100 \mu \mathrm{l}$, followed by $8 \mathrm{~Gy}$ radiation after the last RG108 treatment). Both DMSO and RG108 were intraperitoneally injected. The tumor sizes were assessed with digital calipers at regular intervals and their volumes were calculated according to the following formula: tumor volume $=0.52 \mathrm{x}$ length $\mathrm{x}$ width $^{2}(14)$. Tumor growth curves were produced and data are presented as the mean \pm SEM. The animals were sacrificed 30 days after the first inoculation and their tumors were frozen at $-80^{\circ} \mathrm{C}$ or fixed in $10 \%$ formalin overnight and subjected to 
A

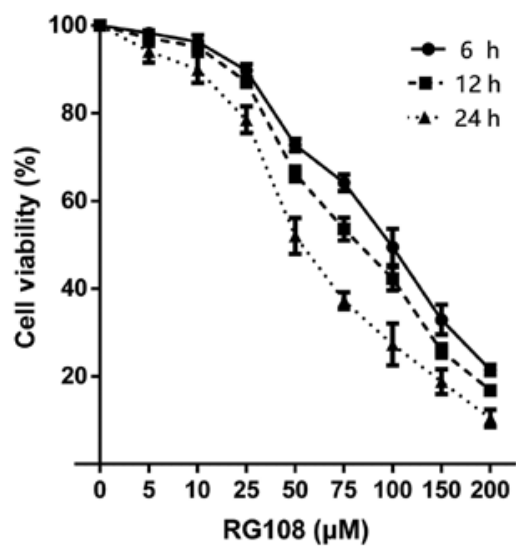

C

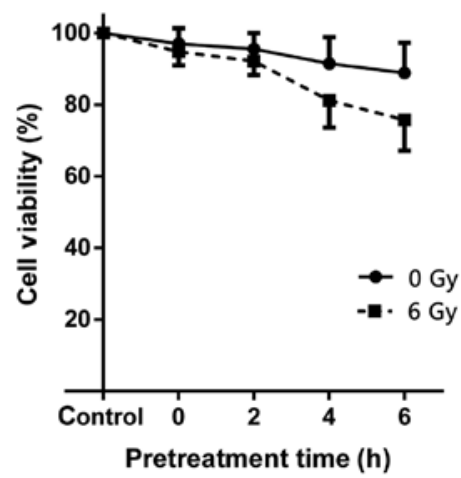

B

TE-1

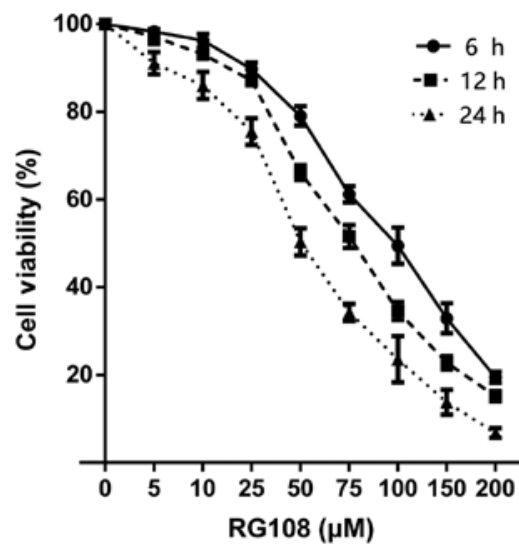

TE-1

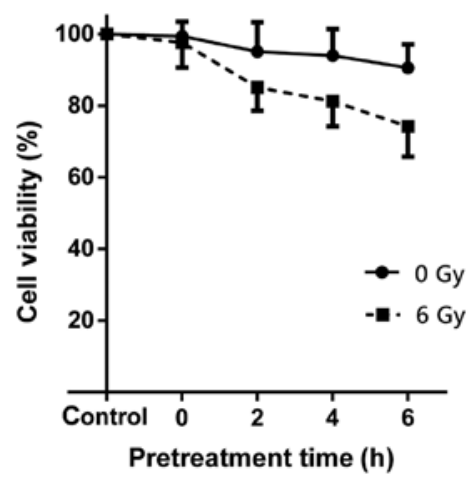

Figure 1. Cytotoxicity of RG108 on Eca-109 and TE-1 cells in vitro. MTT assays were used to assess the viability of (A) Eca-109 and (B) TE-1 cells incubated with various concentrations of RG108 for 6, 12 or $24 \mathrm{~h}$. (C) Eca-109 and (D) TE-1 cells were incubated with a non-toxic dose of RG108 for 0,2, 4 or $6 \mathrm{~h}$ before receiving 0 or $6 \mathrm{~Gy}$ of X-ray irradiation. Subsequently, the cells were incubated for another $48 \mathrm{~h}$ and their viability was assessed. The viability of control cells was normalized to $100 \%$. Data are presented as the mean \pm SEM of three independent experiments.

IHC analysis. The animal experiments were approved by the Institutional Animal Care and Use Committee of Soochow University.

RNA-seq analysis of gene expression. Total RNA was extracted from cells with TRIzol reagent (Invitrogen Life Technologies, Carlsbad, CA, USA). RNA purity was checked using a Nano Photometer ${ }^{\circledR}$ spectrophotometer (Implen Inc., Westlake Village, CA, USA) and RNA concentrations were assessed using a Qubit ${ }^{\circledR}$ RNA Assay kit with a Qubit ${ }^{\circledR}$ 2.0 Fluorometer (Invitrogen Life Technologies). The transcriptome library for sequencing was generated using a VAHTSTM mRNA-seq v2 Library Prep Kit for Illumina ${ }^{\circledR}$ (Vazyme Biotech Co., Ltd, Nanjing, China) and the index-coded samples were clustered using VAHTS RNA Adapters set1/set2 for Illumina (Vazyme Biotech) according to the manufacturer's instructions. After clustering, the libraries were sequenced on an Illumina Hiseq X Ten platform using a (2x150 bp) paired-end module. The raw images were transformed into raw reads by base calling using CASAVA 1.8 (http://www.illumina.com/support/ documentation.ilmn). In addition, cluster analysis, Gene Ontology (GO) and pathway enrichment analysis (KOBAS 2.0) of differentially expressed genes were implemented.

Statistical analysis. Data are presented as the mean \pm SEM from three independent experiments. Differences were analyzed using Student's t-test when only two groups were present, while differences among more than two groups were tested by one-way analysis of variance (ANOVA). The interaction between RG108 and radiation was assessed using two-way ANOVA for both in vitro and in vivo efficacy assays. SPSS 19.0 (SPSS, Inc., Chicago, IL, USA) was used for all statistical analyses. Differences were considered statistically significant when $\mathrm{P}<0.05$.

\section{Results}

Growth inhibition effects of RG108 in EC cells. To evaluate the inhibitory effects of RG108 on the growth of the cultured human EC cell lines Eca-109 and TE-1, we first tested whether RG108 alone, at a range of different concentrations, inhibited the proliferation of human EC cells. The results indicated that RG108 inhibited cell proliferation in both Eca-109 and TE-1 cells in a dose- and time-dependent manner (Fig. 1A and B). The $50 \%$ inhibitory concentrations $\left(\mathrm{IC}_{50}\right)$ of $\mathrm{RG} 108$ against Eca-109 and TE-1 cells were 70 and $75 \mu \mathrm{M}$, respectively. We selected $25 \mu \mathrm{M}$ RG108, which resulted in $\sim 90 \%$ cell viability, as the non-toxic dose for the subsequent experiments.

We next assessed whether pretreatment with RG108 enhanced the anti-proliferative effect of irradiation on EC cells. The results revealed that pretreatment with $25 \mu \mathrm{M}$ of RG108 inhibited proliferation of both cell lines in a time-dependent 
A
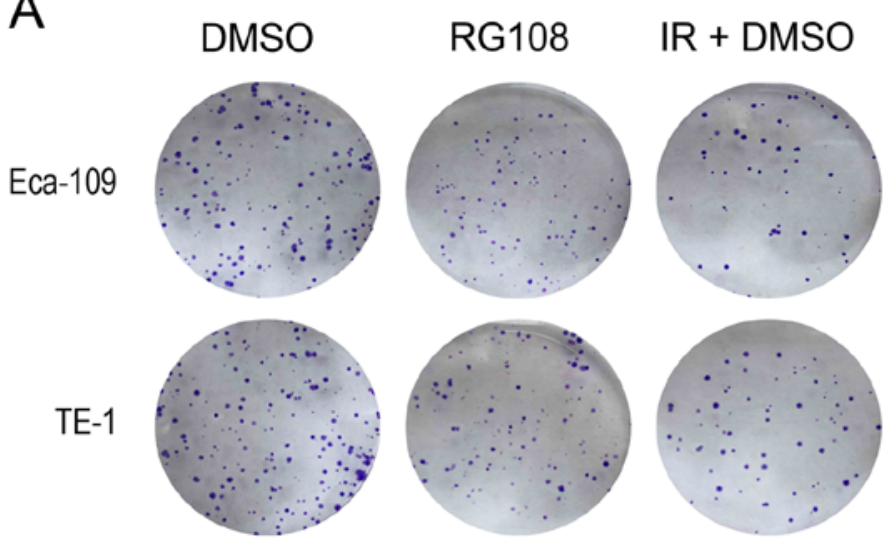

IR + RG108

B
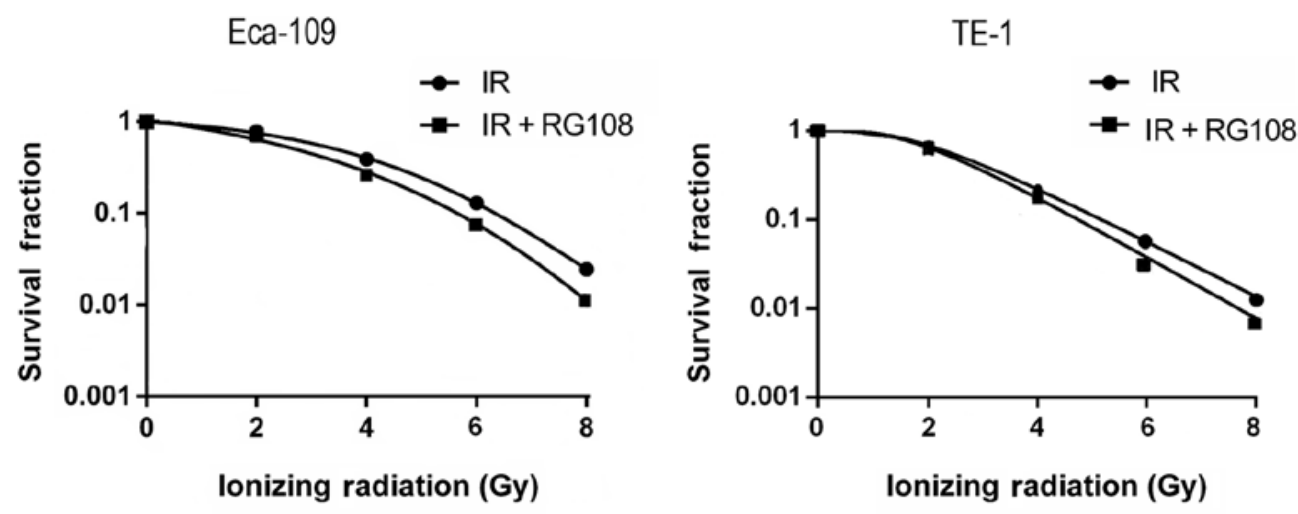

\begin{tabular}{cccc}
\hline Group & $D_{0}$ & $D_{q}$ & SER \\
\hline IR & 1.249 & 1.921 & \\
IR+RG108 & 1.026 & 1.546 & 1.217 \\
\hline
\end{tabular}

\begin{tabular}{cccc}
\hline Group & $\mathrm{D}_{0}$ & $\mathrm{D}_{\mathrm{q}}$ & $\mathrm{SER}$ \\
\hline $\mathrm{IR}$ & 1.402 & 1.988 & \\
$\mathrm{IR}+\mathrm{RG} 108$ & 1.259 & 1.883 & 1.113 \\
\hline
\end{tabular}

Figure 2. Colony formation assay for analyzing the effect of RG108 on the radiosensitivity of Eca-109 and TE-1 cells. (A) Colony formation assays and (B) clonogenic cell survival curves were generated. The data were normalized to those of the unirradiated control cells. $\mathrm{D}_{0}, \mathrm{D}_{\mathrm{q}}$ and calculated SER values for IR and IR + RG108 are shown.

manner (Fig. 1C and D). Given that $6 \mathrm{~h}$ of RG108 pretreatment before IR sensitized the EC cells to IR-induced cell death, this pretreatment time was used for further studies.

RG108 at a non-toxic dose reduces focus formation and enhances the anti-growth effect of radiation in both Eca-109 and TE-1 cells. Clonogenic assays were performed to investigate the effect of a low RG108 dose on the radiosensitivity of EC cell lines. Firstly, we examined the clonogenicity of cells after treatment with $25 \mu \mathrm{M}$ RG108 or an equivalent volume of DMSO (control) for $6 \mathrm{~h}$ with or without IR. As shown in Fig. 2A, the number of colonies after treatment with $25 \mu \mathrm{M}$ RG108 and 6 Gy of X-ray irradiation was significantly decreased compared with the control $(\mathrm{P}<0.05)$ for both Eca-109 and TE-1 cells. Thus, RG108 reduced the radioresistance of both Eca-109 and TE-1 cells (SER = 1.217, Fig. 2B). These results demonstrated that a non-toxic dose of RG108 $(25 \mu \mathrm{M})$ decreased focus formation and significantly reduced the radioresistance of EC cells.

RG108 modulates apoptosis of human EC cells after IR. To investigate whether RG108 at a non-toxic dose could enhance radiation-induced apoptosis in EC cells, we performed Annexin V/7-AAD double-staining assays to analyze cellular apoptosis. As depicted in Fig. 3A and B, compared with control cells, apoptosis was modestly increased in both cell lines by treatment with RG108 or IR alone. However, apoptosis was significantly increased by treating cells with $25 \mu \mathrm{M}$ RG108 for $6 \mathrm{~h}$ before exposure to IR in both cell lines.

Subsequently, we examined whether RG108 can regulate the expression of genes associated with apoptosis by western blot analysis. The results revealed that pretreatment with $25 \mu \mathrm{M}$ RG108 for $6 \mathrm{~h}$ before $6 \mathrm{~Gy}$ irradiation significantly inhibited the expression of Bcl-2, while it upregulated the expression of Bax, in both Eca-109 and TE-1 cells (Fig. 3C). Collectivelly, these results indicated that apoptosis of EC cells was significantly increased by RG108 at a range of non-toxic doses in combination with IR.

RG108 combined with IR enhances G2/M cell cycle arrest in EC cells. Eca-109 and TE-1 cells were mock treated or pretreated with $25 \mu \mathrm{M}$ RG108 for $6 \mathrm{~h}$. Subsequently, the cells were exposed to IR and the cell cycle was analyzed after $48 \mathrm{~h}$. As demonstrated in Fig. 4, compared with the control group, 
A
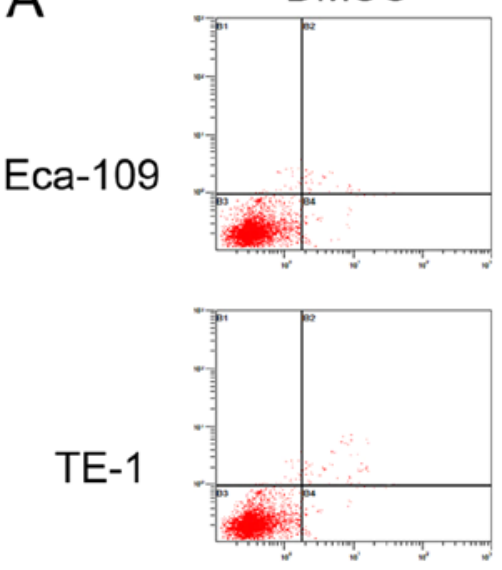

B

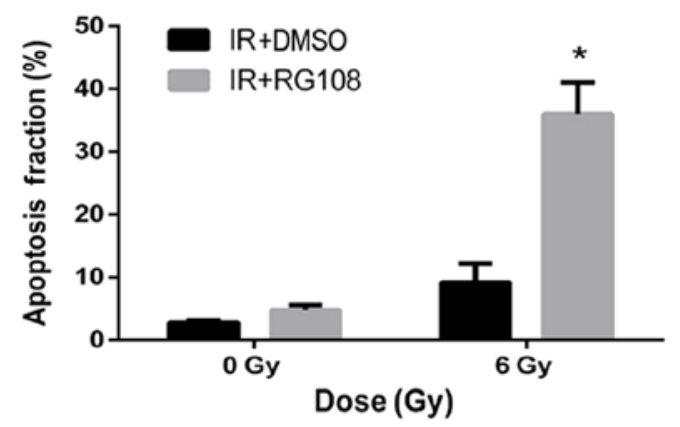

TE-1

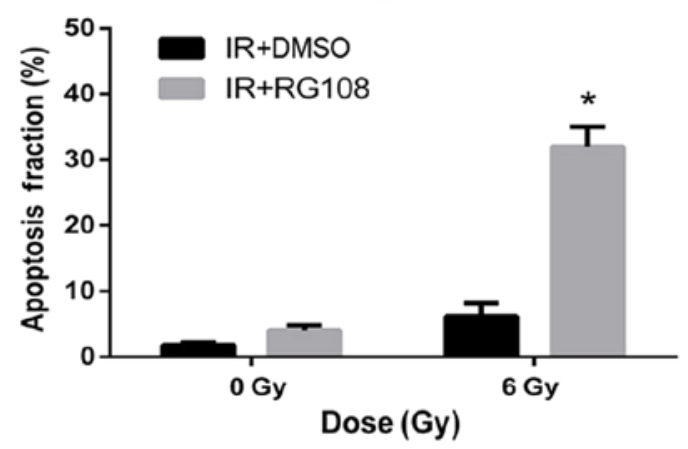

$\mathrm{IR}+\mathrm{DMSO}$
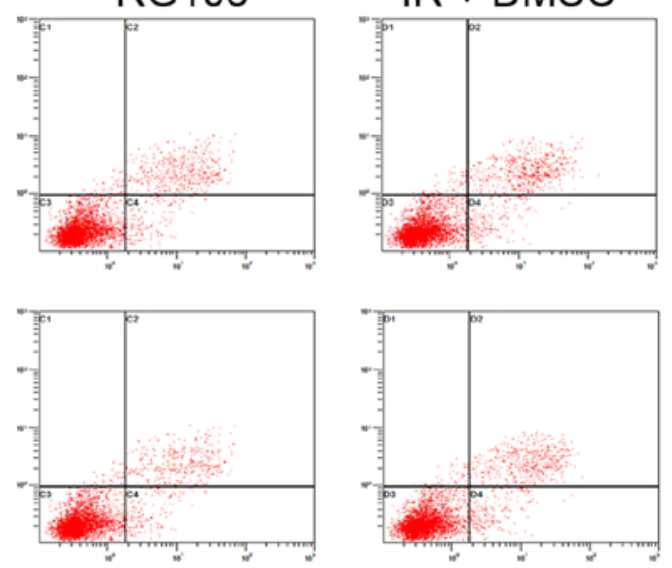

C

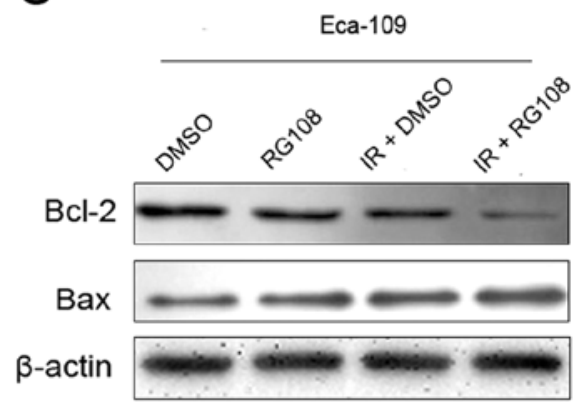

TE-1

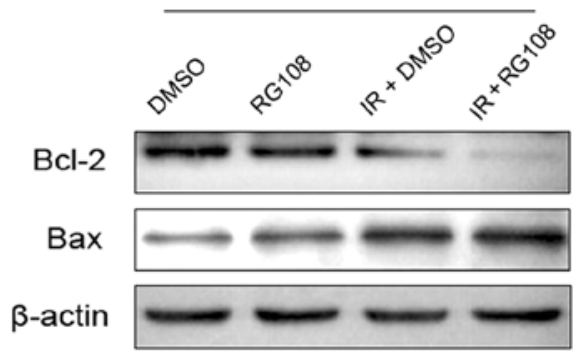

Figure 3. Induction of apoptosis by RG108 and/or IR in EC cells. (A) Eca-109 and TE-1 cells were treated with $25 \mu$ M RG108 or DMSO for 6 h before being exposed to $6 \mathrm{~Gy}$ of X-ray irradiation. The percentage of apoptotic cells was evaluated $48 \mathrm{~h}$ later by flow cytometry. Data are presented as the mean \pm SEM ( $\mathrm{P}<0.05$ compared with control treatment). (C) Western blot analysis of apoptosis-related proteins including Bcl-2 and Bax.

pretreatment with $25 \mu \mathrm{M}$ RG108 alone did not change the distribution of the cell cycle phases in either of the two cell lines. While 6 Gy of X-ray irradiation alone induced a slight increase of Eca-109 and TE-1 cells in G2/M phase, pretreatment with $25 \mu \mathrm{M}$ RG108 for $6 \mathrm{~h}$ in combination with IR significantly increased this radiation-induced arrest inthe G2/M phase by $9.77 \%$ in Eca-109 cells and $7.97 \%$ in TE-1 cells (both $\mathrm{P}<0.05$ ). These results indicated that combined treatment with RG108 and IR increased the G2/M arrest of the EC cells induced by radiation.

RG108 inhibits tumor growth and enhances radiosensitivity in a mouse xenograft model. To examine the inhibitory effect of RG108 on EC-cell growth in vivo, the Eca-109 cells were subcutaneously inoculated into the right posterior flank region of 5-week-old male BALB/c nude mice. When tumors reached
$150-200 \mathrm{~mm}^{3}$ in volume, the mice were randomly divided into four groups. Either DMSO or RG108 was intraperitoneally injected into mice daily for 6 days. Mice in each group exhibited no differences in body weight and no observable pathological abnormalities (data not shown), indicating no gross toxicity. As demonstrated in Fig. 5A and B, treatment with RG108 or IR alone slightly decreased the xenograft size, whereas the combination of RG108 and IR significantly decreased the volume of tumors compared with the control treatment $(57 \%$ reduction, $\mathrm{P}<0.05)$.

RG108 inhibits angiogenesis and cell proliferation in response to $X$-ray irradiation in vivo. To characterize the molecular changes of the xenografts, the proliferation marker Ki67 and angiogenesis marker CD31 were examined. As depicted in Fig. 6 (top), RG108 or IR alone modestly reduced the expres- 
A

DMSO

RG108

$\mathrm{IR}+\mathrm{DMSO}$

$\mathrm{IR}+\mathrm{RG} 108$
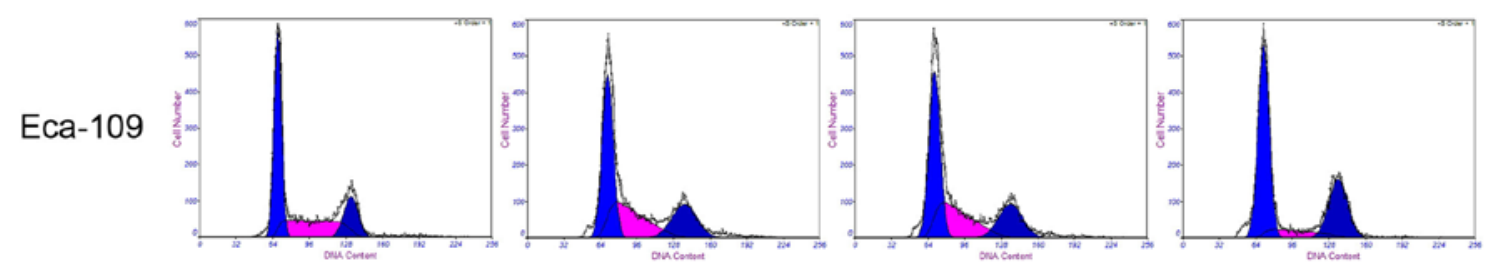

TE-1
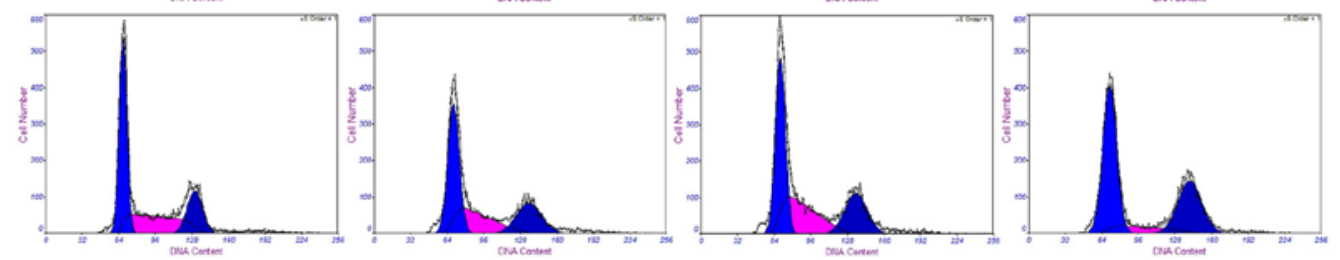

B

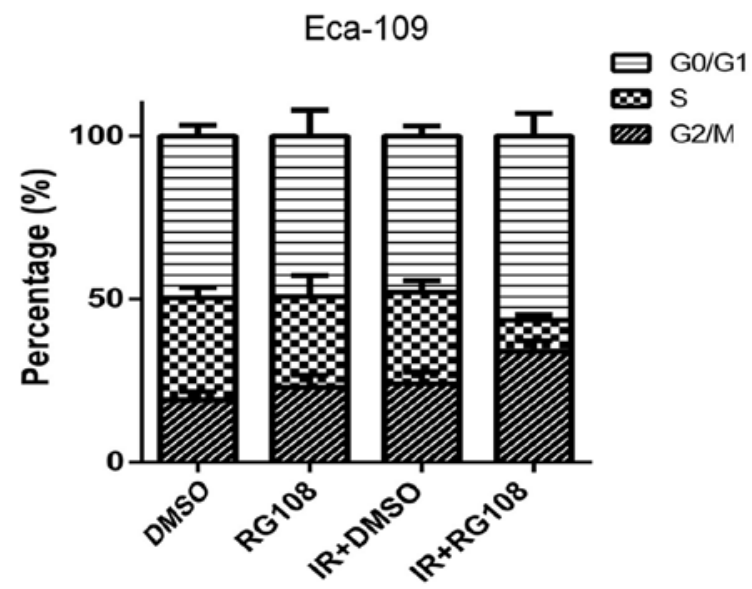

TE-1

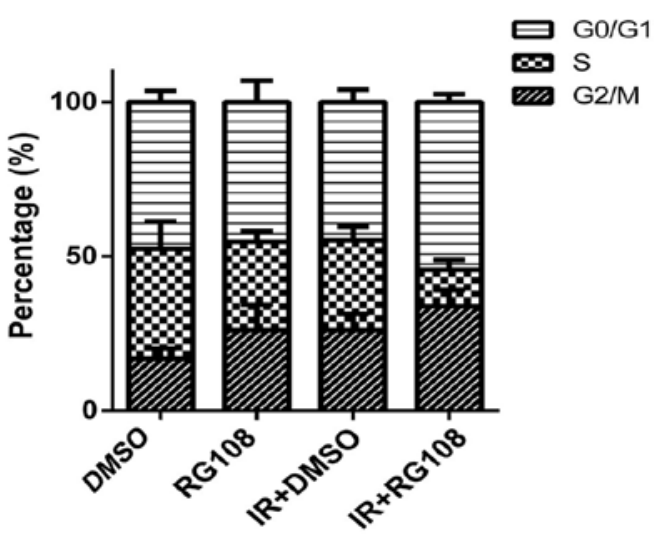

Figure 4. RG108 disturbs the cell cycle of EC cells after IR. (A) The cell cycle distributions of the Eca-109 and TE-1 cells were assessed using flow cytometry. (B) Quantification of the cell cycle distributions after the indicated treatments.

A
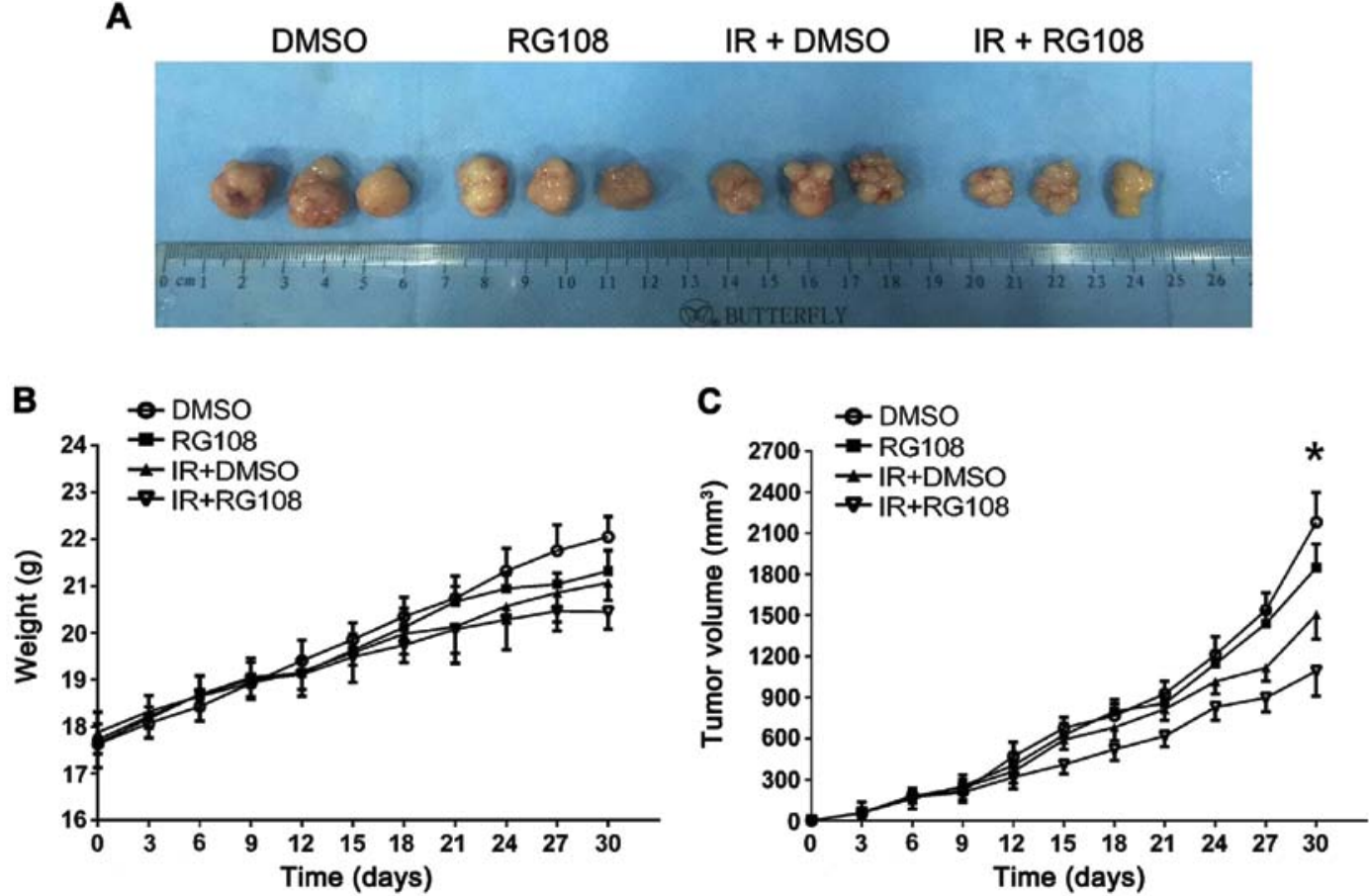

Figure 5. Effects of RG108 on the tumor growth of xenografts. Eca-109 cells were injected into each posterior flank region of five nude mice per treatment group. (A) Representative subcutaneous xenografts from mice of each group at the final time-point. (B) Mouse body weights and (C) tumor sizes were assessed at 3-day intervals. * $\mathrm{P}<0.05$, compared with IR treatment alone. Data are presented as the mean \pm SEM. 


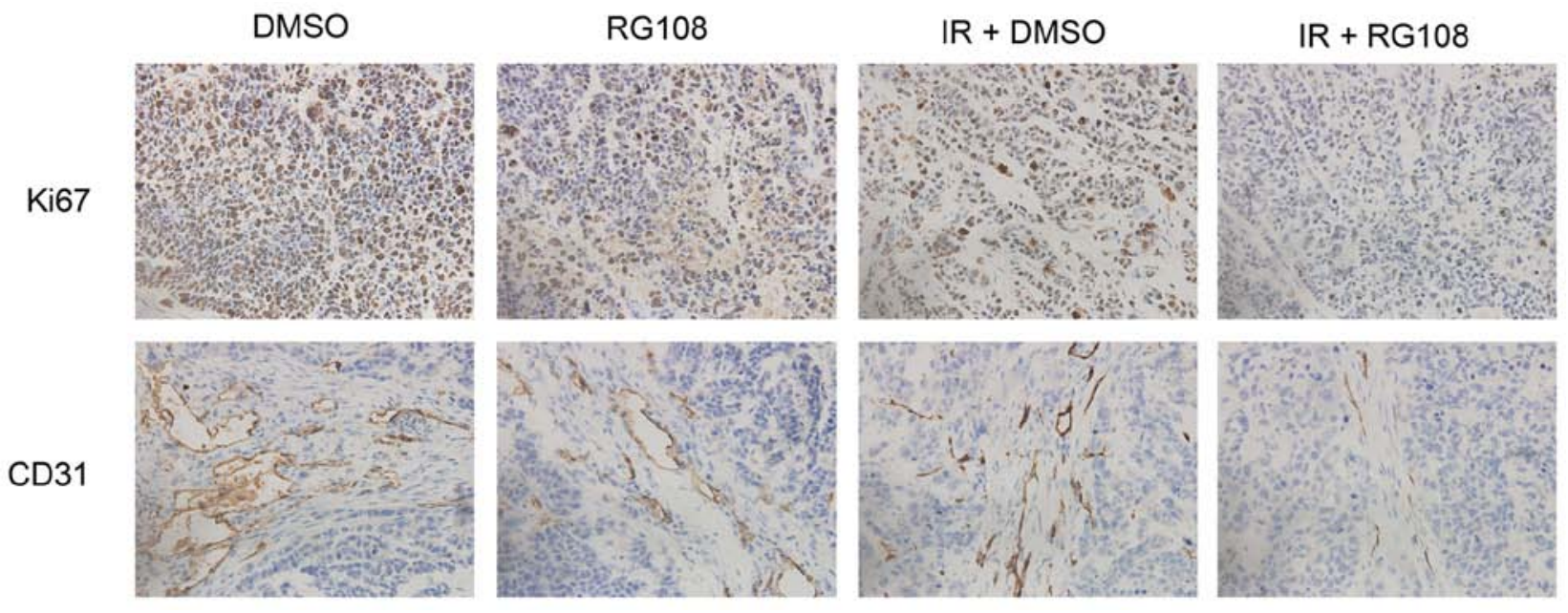

Figure 6. Representative IHC images showing Ki67 and CD31-staining in xenografts from Eca-109 cells (magnification, x400).

A

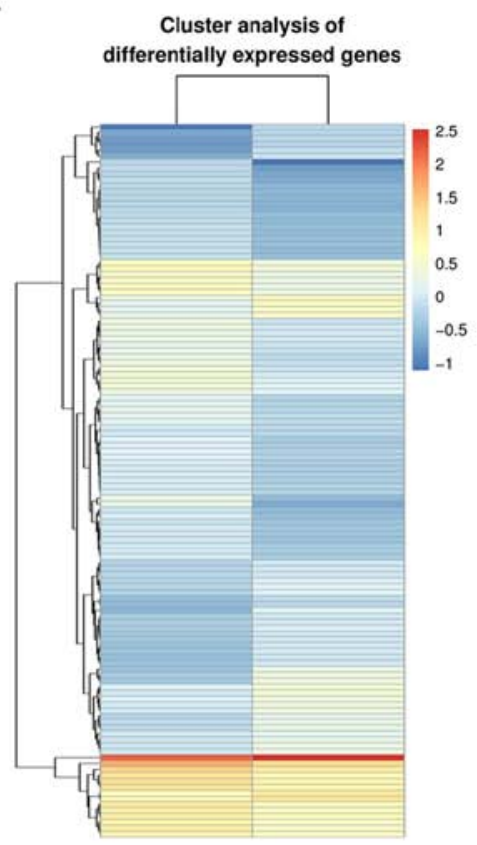

IR
B

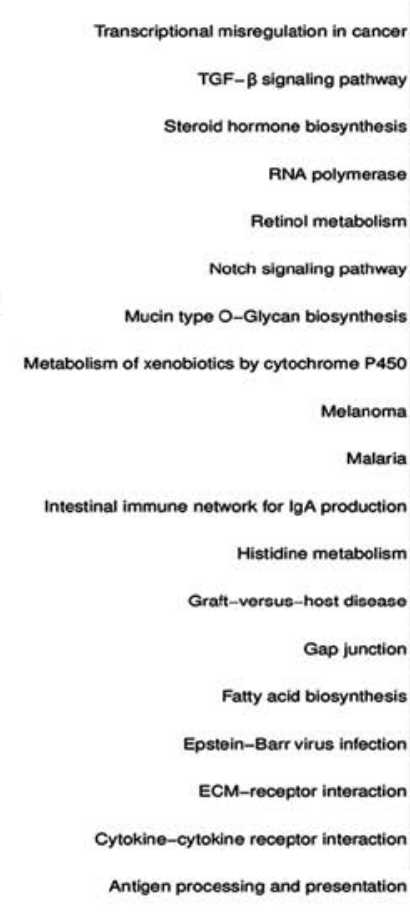

Top 20 enriched pathway

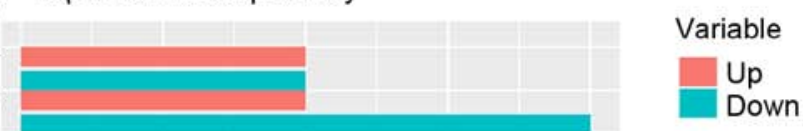

(IR vs. RG108+IR)

Figure 7. Prediction of significant pathways. (A) Heat map of gene expression between Eca-109 cells after 6 Gy of X-ray irradiation and cells treated with a combination of RG108 and irradiation. (B) Significant predicted pathways for the differentially expressed genes.

sion of Ki67, whereas the number of Ki67-positive cells was significantly decreased in Eca-109 tumors by combined treatment with both RG108 and IR $(\mathrm{P}<0.05)$. Similarly, compared to treatment with RG108 or IR alone, the combination therapy significantly reduced tumor angiogenesis $(\mathrm{P}<0.05)$. As shown in Fig. 6 (bottom), treatment with RG108 or IR alone modestly reduced the expression of $\mathrm{CD} 31$, but combined treatment with both RG108 and IR significantly decreased the expression of CD31.

RG108 increases the radiosensitivity of Eca-109 cells via a complex mechanism. We profiled the gene expression of
Eca-109 cells after either 6 Gy of X-ray irradiation or a combination of $25 \mu \mathrm{M}$ RG108 and irradiation to further analyze the underlying mechanisms responsible for RG108-mediated radiosensitivity. RNA-seq analysis identified a total of 121 genes (45 upregulated and 76 downregulated) with significantly altered expression levels ( $\log 2$ ratiol $\geq 1$ and P-value $<0.05$ ) between the two treatments (Tables I and II). RG108 appeared to modulate the radiosensitivity of Eca-109 cells via a complex mechanism. Pathway analysis revealed that RG108 treatment affected multiple pathways, including the TGF- $\beta$ signaling pathway and Epstein-Barr virus infection pathway (Fig. 7). 
Table I. Microarray analysis of upregulated genes in Eca-109 cells (6 Gy of X-ray irradiation plus RG108 vs. 6 Gy of X-ray irradiation alone).

\begin{tabular}{|c|c|c|c|c|c|}
\hline ID & Gene name & Locus & $\log 2(\mathrm{RG} 108+\mathrm{IR} / \mathrm{ctr}+\mathrm{IR})$ & P-value & Description \\
\hline 1 & $A B H D 14 A-A C Y 1$ & $\operatorname{chr} 3$ & $1.79769 \mathrm{e}+308$ & 0.0000000328 & ABHD14A-ACY1 read-through \\
\hline 2 & LOC 388780 & $\operatorname{chr} 20$ & $1.79769 e+308$ & 0.0007827010 & Uncharacterized LOC388780 \\
\hline 3 & AGAPI-IT1 & $\operatorname{chr} 2$ & $1.79769 \mathrm{e}+308$ & 0.0037878500 & AGAP1 intronic transcript 1 \\
\hline 4 & RNF103-CHMP3 & $\operatorname{chr} 2$ & 3.0834500000 & 0.0008902720 & RNF103-CHMP3 read-through \\
\hline 5 & CNFN & chr19 & 2.4991900000 & 0.0015629000 & Cornifelin \\
\hline 6 & $P I K 3 C D-A S 2$ & chr1 & 2.4472000000 & 0.0048119700 & PIK3CD antisense RNA 2 \\
\hline 7 & $I D 2-A S 1$ & $\operatorname{chr} 2$ & 2.3098600000 & 0.0037836900 & ID2 antisense RNA 1 (head to head) \\
\hline 8 & SLMO2-ATP5E & $\operatorname{chr} 20$ & 2.2677500000 & 0.0002843230 & SLMO2-ATP5E read-through \\
\hline 9 & $A M T N$ & chr4 & 2.2395500000 & 0.0057826300 & Amelotin \\
\hline 10 & $F 2 R L 2$ & $\operatorname{chr} 5$ & 2.0639000000 & 0.0003827790 & Coagulation factor II thrombin receptor like 2 \\
\hline 11 & ZNF559-ZNF177 & $\operatorname{chr} 19$ & 2.0248700000 & 0.0050070200 & ZNF559-ZNF177 read-through \\
\hline 12 & GCOM1, MYZAP & $\operatorname{chr} 15$ & 1.8443900000 & 0.0000197514 & GRINL1A complex locus 1 \\
\hline 13 & Clorf53 & chr1 & 1.7266700000 & 0.0000011706 & Chromosome 1 open reading frame 53 \\
\hline 14 & MMP13 & $\operatorname{chr} 11$ & 1.6353900000 & 0.0021975000 & Matrix metallopeptidase 13 \\
\hline 15 & TOPORS-AS1 & $\operatorname{chr} 9$ & 1.6260200000 & 0.0043661900 & TOPORS antisense RNA 1 \\
\hline 16 & RPS10-NUDT3 & chr6 & 1.5762500000 & 0.0000082438 & RPS10-NUDT3 read-through \\
\hline 17 & C7orf55-LUC7L2 & $\operatorname{chr} 7$ & 1.5491400000 & 0.0000433101 & C7orf55-LUC7L2 read-through \\
\hline 18 & FAM9B & $\operatorname{chrX}$ & 1.4650900000 & 0.0002975920 & Family with sequence similarity 9 member B \\
\hline 19 & GGACT & $\operatorname{chr} 13$ & 1.4237200000 & 0.0003725270 & $\gamma$-glutamylamine cyclotransferase \\
\hline 20 & EVAlA & $\operatorname{chr} 2$ & 1.3947700000 & 0.0071589000 & $\begin{array}{l}\text { Eva-1 homolog A, regulator of programmed } \\
\text { cell death }\end{array}$ \\
\hline
\end{tabular}

Table II. Microarray analysis of downregulated genes in Eca-109 cells (6 Gy of X-ray irradiation plus RG108 vs. 6 Gy of X-ray irradiation alone).

\begin{tabular}{|c|c|c|c|c|c|}
\hline ID & Gene name & Locus & $\log 2(\mathrm{RG} 108+\mathrm{IR} / \mathrm{ctr}+\mathrm{IR})$ & P-value & Description \\
\hline 1 & FOXB1 & chr15 & -3.2752 & 0.0021565800 & Forkhead box B1 \\
\hline 2 & RDH5 & $\operatorname{chr} 12$ & -3.0106 & 0.0003470500 & Retinol dehydrogenase 5 \\
\hline 3 & C19orf71 & chr19 & -2.85166 & 0.0001936530 & Chromosome 19 open reading frame 71 \\
\hline 4 & $R H A G$ & chr6 & -2.17175 & 0.0020515500 & $\mathrm{Rh}$-associated glycoprotein \\
\hline 5 & CNTD2 & chr19 & -1.83579 & 0.0006623760 & Cyclin $\mathrm{N}$-terminal domain containing 2 \\
\hline 6 & $M A F B$ & $\operatorname{chr} 20$ & -1.76114 & 0.0000580816 & MAF bZIP transcription factor B \\
\hline 7 & GATSL3 & $\operatorname{chr} 22$ & -1.62313 & 0.0030739500 & GATS protein-like 3 \\
\hline 8 & $I N O 80 B-W B P I$ & $\operatorname{chr} 2$ & -1.60966 & 0.0000335464 & $\begin{array}{l}\text { INO80B-WBP1 read-through (NMD } \\
\text { candidate) }\end{array}$ \\
\hline 9 & YPEL1 & $\operatorname{chr} 22$ & -1.57025 & 0.0002142530 & Yippee like 1 \\
\hline 10 & POCIB-GALNT4 & chr12 & -1.46739 & 0.0000269476 & POC1B-GALNT4 read-through \\
\hline 11 & LOC100507472 & $\operatorname{chr} 15$ & -1.45729 & 0.0000060501 & Uncharacterized LOC100507472 \\
\hline 12 & LOC 389199 & chr4 & -1.45482 & 0.0010464800 & Uncharacterized LOC389199 \\
\hline 13 & $A M D H D 1$ & $\operatorname{chr} 12$ & -1.45002 & 0.0000036856 & Amidohydrolase domain containing 1 \\
\hline 14 & SOX7 & chr8 & -1.42999 & 0.0002313520 & SRY-box 7 \\
\hline 15 & CHRD & $\operatorname{chr} 3$ & -1.42985 & 0.0015947400 & Chordin \\
\hline 16 & DFNB59 & chr2 & -1.41377 & 0.0070473000 & Deafness, autosomal recessive 59 \\
\hline 17 & ICOSLG & chr21 & -1.40911 & 0.0000000006 & Inducible T-cell costimulator ligand \\
\hline 18 & $C R B 2$ & chr9 & -1.39949 & 0.0000000000 & Crumbs 2 , cell polarity complex component \\
\hline 19 & CYP26B1 & $\mathrm{chr} 2$ & -1.3987 & 0.0000000793 & $\begin{array}{l}\text { Cytochrome P450 family } 26 \text { subfamily B } \\
\text { member } 1\end{array}$ \\
\hline 20 & EIF3CL & $\operatorname{chr} 16$ & -1.35891 & 0.0017581100 & $\begin{array}{l}\text { Eukaryotic translation initiationfactor } 3 \\
\text { subunit C-like }\end{array}$ \\
\hline
\end{tabular}




\section{Discussion}

Radiotherapy is an important treatment for cancer and plays a critical role in the management of human EC. However, radioresistance significantly decreases the efficacy of radiotherapy in the treatment of EC (15). Therefore, the efficacy of radiotherapy is limited both by the total dosage of radiation that can be administeredwithout damaging normal tissues and radioresistance of EC. The resistance of malignant tumor cells to anticancer agents remains the major cause of failure in treating patients with EC.

Tumorigenesis and tumor progression are connected with genetic and epigenetic changes and one of these epigenetic factors is DNA methylation (16). Previous studies have revealed that the methylation statuses of specific genes may potentially be molecular markers of thyroid (17), breast (18), prostate (19), gastric (20) and colon carcinomas (21). The reversion of epigenetic mutations by DNMTIs, a promising class of novel drugs, represents an experimental strategy with great promise for epigenetic cancer therapy (22). In fact, two nucleoside analogs, 5-azacytidine and 5-aza-2'-deoxycytidine, have already been approved by the US Food and Drug Administration (USFDA) for the treatment of myelodysplastic syndrome (23).

Epigenetics and DNA methylation have recently become one of the most exciting frontiers for research on the radioresistance of cancer cells. By integrating mRNA and methylation profiles, Luo et al (24) found that decreased expression of the transcription factor Sall2, with a corresponding increase in methylation of the Sall2 gene, was associated with the aggressive phenotypes acquired by EC cells after radiotherapy (24). RG108, the first DNMTi discovered by rational drug design, functions without being integrated into DNA and effectively blocks DNMTs at their active sites. This leads to reactivation of tumor-suppressor genes and demethylation of genomic DNA, while exhibiting little toxicity in human cancer cell lines $(12,25)$. The present study first illustrated the role of RG108 in EC cell proliferation and radiosensitivity.

To date, apoptosis has been the most widely studied mechanism in anticancer therapy $(26,27)$. In the present study, we found that pretreatment with RG108 prior to IR increased apoptosis of EC cells via the overexpression of Bax, accompanied by a reduction of Bcl-2. As demonstrated in a previous study (28), Bcl-2 and Bax are two members of the Bcl-2 family, which is composed of both apoptosis-promoting and antiapoptotic proteins that exert opposing effects on mitochondria. Increased expression of Bcl-2 (an anti-apoptotic protein) is involved in the development and progression of many tumor types. The present study demonstrated that RG108 increased the radiosensitivity and promoted apoptosis of EC cells both in vitro and in vivo. However, in the in vivo experiments, RG108 was administered at a concentration of $50 \mathrm{mg} / \mathrm{kg}$ to achieve effective mouse blood concentrations. Further investigation with other levels of RG108 is needed. The degradation of cyclin B1 has been reported to be a novel phenomenon that is caused by high-dose radiation, leading to G2/M cell-cycle arrest and sensitivity to radiotherapy, although the mechanism of this cell-cycle suspension is still under investigation (29). Zheng et al (30) and Liu et al (31) have reported that treatment with either miRNA-200c or MG132 promoted G2/M arrest in cancer cells, leading to the conclusion that strategies that target
G2/M arrest may be effective for promoting radiosensitivity in cancer therapy. These previously mentioned results support the conclusion of the present study that RG108 holds promise as an effective radiosensitizer in EC therapy by increasing $\mathrm{G} 2 / \mathrm{M}$ arrest.

Analysis of mRNA expression indicated that RG108 combined with IR treatment increased the expression of EVA1A, which in most cancer tissues has reduced or undetectable expression compared to normal tissues $(32,33)$. The restoration of EVA1A expression induces death in some cancer cell lines through both autophagy and apoptosis, indicating that EVA1A is an effective tumor-suppressing molecule. RG108 combined with radiotherapy increased the expression of EVA1A, which may be one of the reasons why RG108 inhibited tumor growth. The present study also revealed that RG108 modulated the radiosensitivity of Eca-109 cells via a complex mechanism by affecting multiple pathways, including the TGF- $\beta$ signaling pathway and Epstein-Barr virus infection pathway.

In the present study, we elucidated the effects of RG108 and IR on the growth of EC cells. The results revealed that RG108 inhibited the growth of EC cells by increasing cell apoptosis and G2/M arrest. The results of tumor xenograft experiments revealed that RG108, combined with IR, significantly inhibited the proliferation of Eca-109 cells in vivo. RNA-seq analysis demonstrated that, compared with radiation treatment alone, X-ray irradiation plus RG108 altered the expression of 121 genes that function in multiple pathways, including the TGF- $\beta$ signaling pathway and Epstein-Barr virus infection pathway. In conclusion, RG108 enhanced radiation-induced apoptosis and increased G2/M arrest in EC, thus showing promise as an effective radiosensitizer in EC therapy. However, the effects of RG108 on tumorigenesis and the value of its application for treating other cancers require further study.

\section{Acknowledgements}

This study was supported by the Jiangsu Provincial Special Program of Medical Science (nos.BE2015631and BK20161152), the Medicine and Health and Scientific Development Program of Shandong Province (no. 2015WSB30011), the Scientific Research of Changzhou (nos. QN201503 and CJ20160015), the Scientific Research of Jintan (no. JT2016065) and the Changzhou High Level Medical Talents Training Project (no. 2016CZLJ026).

\section{References}

1. Siegel R, Ma J, Zou Z and Jemal A: Cancer statistics, 2014. CA Cancer J Clin 64: 9-29, 2014.

2. Lozano R, Naghavi M, Foreman K, Lim S, Shibuya K, Aboyans V, Abraham J, Adair T, Aggarwal R, Ahn SY, et al: Global and regional mortality from 235 causes of death for 20 age groups in 1990 and 2010: A systematic analysis for the Global Burden of Disease Study 2010. Lancet 380: 2095-2128, 2012.

3. Zhang C, Chen X, Li L, Zhou Y, Wang C and Hou S: The Association between telomere length and cancer prognosis: Evidence from a meta-analysis. PLoS One 10: e0133174, 2015.

4. Ito S, Ohga T, Saeki H, Nakamura T, Watanabe M, Tanaka S, Kakeji Y and Maehara Y: p53 mutation profiling of multiple esophageal carcinoma using laser capture microdissection to demonstrate field carcinogenesis. Int J Cancer 113: 22-28, 2005.

5. Kuwano H, Kato H, Miyazaki T, Fukuchi M, Masuda N, Nakajima M, Fukai Y, Sohda M, Kimura H and Faried A: Genetic alterations in esophageal cancer. Surg Today 35: 7-18, 2005. 
6. Karahoca M and Momparler RL: Pharmacokinetic and pharmacodynamic analysis of 5-aza-2'-deoxycytidine (decitabine) in the design of its dose-schedule for cancer therapy. Clin Epigenetics 5: 3, 2013.

7. Singh V, Sharma P and Capalash N: DNA methyltransferase-1 inhibitors as epigenetic therapy for cancer. Curr Cancer Drug Targets 13: 379-399, 2013.

8. Borges S, Döppler H, Perez EA, Andorfer CA, Sun Z, Anastasiadis PZ, Thompson E, Geiger XJ and Storz P Pharmacologic reversion of epigenetic silencing of the PRKD1 promoter blocks breast tumor cell invasion and metastasis. Breast Cancer Res 15: R66, 2013.

9. Karpf AR, Moore BC, Ririe TO and Jones DA: Activation of the p53 DNA damage response pathway after inhibition of DNA methyltransferase by 5-aza-2'-deoxycytidine. Mol Pharmacol 59: 751-757, 2001.

10. Eiseler T, Döppler H, Yan IK, Goodison S and Storz P: Protein kinase D1 regulates matrix metalloproteinase expression and inhibits breast cancer cell invasion. Breast Cancer Res 11: R13, 2009.

11. Jüttermann R, Li E and Jaenisch R: Toxicity of 5-aza-2'-deoxycytidine to mammalian cells is mediated primarily by covalent trapping of DNA methyltransferase rather than DNA demethylation. Proc Natl Acad Sci USA 91: 11797-11801, 1994

12. Brueckner B, Garcia Boy R, Siedlecki P, Musch T, Kliem HC Zielenkiewicz P, Suhai S, Wiessler M and Lyko F: Epigenetic reactivation of tumor suppressor genes by a novel small-molecule inhibitor of human DNA methyltransferases. Cancer Res 65 : 6305-6311, 2005.

13. Bardenheuer W, Lehmberg K, Rattmann I, Brueckner A, Schneider A, Sorg UR, Seeber S, Moritz T and Flasshove M: Resistance to cytarabine and gemcitabine and in vitro selection of transduced cells after retroviral expression of cytidine deaminase in human hematopoietic progenitor cells. Leukemia 19: 2281-2288, 2005.

14. Wang Z, Hou J, Lu L, Qi Z, Sun J, Gao W, Meng J, Wang Y, Sun H, Gu H, et al: Small ribosomal protein subunit $\mathrm{S} 7$ suppresses ovarian tumorigenesis through regulation of the PI3K/AKT and MAPK pathways. PLoS One 8: e79117, 2013.

15. Shridhar R, Almhanna K, Meredith KL, Biagioli MC Chuong MD, Cruz A and Hoffe SE: Radiation therapy and esophageal cancer. Cancer Contr 20: 97-110, 2013.

16. Jones PA and Baylin SB: The epigenomics of cancer. Cell 128: 683-692, 2007.

17. Hoque MO, Rosenbaum E, Westra WH, Xing M, Ladenson P, Zeiger MA, Sidransky D and Umbricht CB: Quantitative assessment of promoter methylation profiles in thyroid neoplasms. J Clin Endocrinol Metab 90: 4011-4018, 2005.

18. Miyamoto K, Fukutomi T, Akashi-Tanaka S, Hasegawa T, Asahara T, Sugimura T and Ushijima T: Identification of 20 genes aberrantly methylated in human breast cancers. Int J Cancer 116 : 407-414, 2005.

19. McKie AB, Douglas DA, Olijslagers S, Graham J, Omar MM, Heer R, Gnanapragasam VJ, Robson $\mathrm{CN}$ and Leung HY: Epigenetic inactivation of the human sprouty2 (hSPRY2) homologue in prostate cancer. Oncogene 24: 2166-2174, 2005.
20. An C, Choi IS, Yao JC, Worah S, Xie K, Mansfield PF, Ajani JA, Rashid A, Hamilton SR and Wu TT: Prognostic significance of $\mathrm{CpG}$ island methylator phenotype and microsatellite instability in gastric carcinoma. Clin Cancer Res 11: 656-663, 2005.

21. Feinberg AP, Cui H and Ohlsson R: DNA methylation and genomic imprinting: Insights from cancer into epigenetic mechanisms. Semin Cancer Biol 12: 389-398, 2002.

22. Egger G, Liang G, Aparicio A and Jones PA: Epigenetics in human disease and prospects for epigenetic therapy. Nature 429: 457-463, 2004.

23. Abdulhaq $\mathrm{H}$ and Rossetti JM: The role of azacitidine in the treatment of myelodysplastic syndromes. Expert Opin Investig Drugs 16: 1967-1975, 2007.

24. Luo J, Wang W, Tang Y, Zhou D, Gao Y, Zhang Q, Zhou X, Zhu H, Xing L and Yu J: mRNA and methylation profiling of radioresistant esophageal cancer cells: The involvement of Sall2 in acquired aggressive phenotypes. J Cancer 8: 646-656, 2017.

25. Stresemann C, Brueckner B, Musch T, Stopper H and Lyko F: Functional diversity of DNA methyltransferase inhibitors in human cancer cell lines. Cancer Res 66: 2794-2800, 2006.

26. Yang H, Tian ST, Wu RY, Chen Y, Mei ZN, Wang CY and Yang GZ: Glycoborinine induces apoptosis through mitochondrial pathway in HepG2 cells. J Asian Nat Prod Res 16: 991-999, 2014.

27. Wimardhani YS, Suniarti DF, Freisleben HJ, Wanandi SI, Siregar NC and Ikeda MA: Chitosan exerts anticancer activity through induction of apoptosis and cell cycle arrest in oral cancer cells. J Oral Sci 56: 119-126, 2014.

28. Oh KJ, Barbuto S, Pitter K, Morash J, Walensky LD and Korsmeyer SJ: A membrane-targeted BID BCL-2 homology 3 peptide is sufficient for high potency activation of BAX in vitro. J Biol Chem 281: 36999-37008, 2006.

29. He J, Li J, Ye C, Zhou L, Zhu J, Wang J, Mizota A, Furusawa Y and Zhou G: Cell cycle suspension: A novel process lurking in $\mathrm{G}_{2}$ arrest. Cell Cycle 10: 1468-1476, 2011.

30. Zheng R, Liu Y, Zhang X, Zhao P and Deng Q: miRNA-200c enhances radiosensitivity of esophageal cancer by cell cycle arrest and targeting P21. Biomed Pharmacother 90: 517-523, 2017.

31. Liu J, Shen W, Tang Y, Zhou J, Li M, Zhu W, Yang H, Wu J, Zhang S and Cao J: Proteasome inhibitor MG132 enhances the antigrowth and antimetastasis effects of radiation in human nonsmall cell lung cancer cells. Tumour Biol 35: 7531-7539, 2014.

32. Xu D, Yang F, He H, Hu J, Lv X, Ma D and Chen YY: Expression of TMEM166 protein in human normal and tumor tissues. Appl Immunohistochem Mol Morphol 21: 543-552, 2013.

33. Sun W, Ma XM, Bai JP, Zhang GQ, Zhu YJ, Ma HM, Guo H, Chen YY and Ding JB: Transmembrane protein 166 expression in esophageal squamous cell carcinoma in Xinjiang, China. Asian Pac J Cancer Prev 13: 3713-3716, 2012.

(i)(9) This work is licensed under a Creative Commons Attribution-NonCommercial-NoDerivatives 4.0 International (CC BY-NC-ND 4.0) License. 